\title{
Exploring Current Music Therapy Practices in India
}

\author{
Priyanka Singh ${ }^{1}$ * \\ 1 Independent scholar in Hindustani music, New Delhi, India \\ *piyasingh20.virgo@gmail.com
}

Received: 4 February 2021 Accepted: 9 October 2021 Published: 1 November 2021

Editor: Tanya Marie Silveira Reviewer: Bhuvanaa Ramesh

\begin{abstract}
The concept of music therapy in India is addressed with different terms such as musical therapy, therapeutic use of music, music or musical healing, Nada Chikitsa, Nada Yoga, Raga Chikitsa, Raga Therapy, संगीतीय उपचार, सांगीतकि चकित्सिसा, etc. People working in this area are addressed as music therapists, music healers, संगीत चकित्सिक, नाद चकित्सिक, etc. With the establishment of organizations like Nada Centre for Music Therapy (2004), The Music Therapy Trust (2005), Indian Association of Music Therapy (2010), and Indian Music Therapy Association (2018), the application of music in various environments for its therapeutic and healing properties has improved. People in India have been working in this field as full-time professionals and part-time healers for almost four decades now. But it is also true that people are still unaware of music therapy practices in India, how it works, how to use music in a therapeutic setting, how changes and improvements must be assessed, where to learn and receive training in music therapy, how to receive professional education in music therapy, etc. Since this profession deals with the physical, mental, and emotional health of people, it is important to establish a more formal training system that is required for any healthcare services. In return, such developments will positively impact music therapy practices in India.

This paper is a small attempt to explore the current music therapy practices in India. For this purpose, a telephonic interview was done with Dr. Nishindra Kinjalk, who is a music therapist, a Doctor of Medicine, and a Sitar as well as a Surbahar player. The interview focused on his comprehensive understanding of music therapy practices, his research, his music application model known as Kinjalk Mode of Music Application or KIMMA, developed by him and his fellow doctors, potential barriers to the expansion of this field, and the future of music therapy in India. Also, a Google Form survey was designed and shared with people working with music therapy in India who had completed any of the certificates, diploma, or degree courses offered by private and government institutes through online, in-person instruction, or distance mode. The Google survey was used to collect their responses to learn about their music therapy practices, therapy methods, interventions, assessment process, and the population they have been working with, etc. The survey respondents included both people trained in music therapy practices and those who use music therapeutical-
\end{abstract}


ly. It is important to recognize that during the writing of this report, India was under complete lockdown due to the Covid pandemic. So, telephonic interviews and online surveys were found appropriate to collect information.

Keywords: Dr. Kinjalk, KIMMA, Indian music therapists, music therapy practices

\section{Introduction}

The modern profession of music therapy is in its initial stage in India. Hospitals, clinics, counseling centers, and rehabilitation centers in India have been providing music as a therapeutic intervention as well as a healing agent for a few years now to the patients suffering from physical, mental, or lifestyle disorders (Mythily, 2010). The National Institute of Mental Health and Neurosciences (NIMHANS) (Hegde, 2020), Kinjalk Diabetes and Heart Care Centre (Kinjalk N., 2020), CK Birla Hospital for Women (Bhowmick, 2019), Indian Head Injury Foundation (IHIF, 2016), Meera Center for Music Therapy (Ravi, n.d.), Tamahar- Centre for Children with Developmental Disabilities (Pai, n.d.), Ananya Child Care and Development Center (Adimulam, n.d.), and Niramaya Wellness Clinic (Vinaya, n.d.) are some of the institutes where music therapy programs are running successfully. Doctors, psychologists, and scholars too have been involved in research based on the hypotheses derived from theoretical knowledge.

Dr. Nishindra Kinjalk has been playing an important role in the field of research and practices of music therapy in India for almost three decades now. He established a perfect blend of knowledge about music and medicine in India. His disciplined training in Indian classical music since childhood, his education in Medicine, and intellectual curiosity to explore the impact of music on health have introduced him to the field of music therapy. With his thorough understanding of music and medical science, he explained that although western countries have made so many developments in music therapy research and application, they have not yet understood the role and selection of appropriate music played in it (Kinjalk N., 2020). Through his years of research and literature review of the studies available from European and American countries, Dr. Kinjalk devised the technique known as the Kinjalk Mode of Music Application or "KIMMA" in 1987.

The KIMMA is used for identifying appropriate music for participants or patients as per their history, mood, suitability, and ailment. Dr. Kinjalk founded the Kinjalk school of music therapy in 1996 to undertake clinical research in the field of music therapy. The school focuses on the use of Indian musical forms as an adjunct to allopathic medicines. Patients are provided with an environment of medicine and music that have been reported to potentially help them in the management of stress-related disorders, hypertension, diabetes mellitus, depression, insomnia, anxiety state, learning difficulties, and Alzheimer-like ailments. Also, the school has been involved in the process of developing a methodology to make a uniform system of music prescription. So far, KIMMA along with other music application approaches, namely Nada Chikitsa, Nadopasana, and Nada Yoga, are some of the techniques devised in India. But according to Dr. Kinjalk, KIMMA is said to be the one that is supported with research and scientific experiments where a patient is matched with relevant music for maximum improvements (Kinjalk N., 2020). KIMMA has been recognized as a landmark contribution in the field of music therapy. According to him, researchers around the world are involved in further research studies to explore more in this method of music therapy.

Research studies conducted in India have shown that music therapy is effective for various conditions. It impacts the heart rate and oxygen saturation in pre-term neonates (Paul, Gupta, Singh, Deorari, \& Pandey, 1999). It is suitable for decreasing intraoperative sedative requirements under spinal anesthesia as a non-pharmacological alternative (which does not involve the use of medication to treat pain) (Bansal et al., 2010). Music therapy is found effective on body, mind, and brain of patients with diseases including heart, brain problems, mental and emotional problems (Banerjee, 
Shankha, Sengupta, \& Ghosh, 2015), and for hypertensive elders (Lakshmi \& Sharma, 2015). It is also effective for various anesthetic medications during cardiopulmonary bypass (relating to the heart and lungs) (Kar, Ganguly, Roy, \& Goswami, 2015), pain and anxiety levels of cancer patients (Krishnaswami \& Nair, 2016), and pulmonary rehabilitation in the patients of chronic obstructive pulmonary disease (Sobana, Sunder, \& Jaiganesh, 2020). Apart from these recorded effects, music therapy impacts the academic performance of nursing students (Indira et al., 2018). It has positive impacts on depression, anxiety, and stress levels of patients with depression (Sunitha, Algoodkar, \& Smitha, 2018), and helps to reduce the severity of depression among patients diagnosed with depression (Algoodkar \& Sunitha, 2019). It is also found useful in improving the social skills of autistic children (Bharathi, Venugopal, \& Vellingiri, 2019), and social and emotional skills of children with ADHD (Mahendran \& Jagdeesan, 2017). Such findings have made it helpful to understand the practical applications of Indian music in the various physical, mental, and emotional states of human beings.

Research studies from an Indian perspective motivate more exploration in this field. Here, we can see the important roles played by various music therapy organizations, wellness and therapy centers, music therapy units established by various hospitals within their campuses, professional music therapists, psychologists, counselors, and musicians too. But how a music therapist works within a therapy session, what type of methods and interventions are applied by the therapists, how they assess the improvements or changes, and many questions related to practical aspects of a therapy session need to be answered and reviewed. Therefore, this paper is an effort to explore various aspects of music therapy practices in India.

\section{Background}

Being one of the oldest musical traditions prevalent in the world, Indian music has a historical connection with the tradition of using music and musical sound (nada) to heal, soothe and cure. Further, it is believed that the Vedas have references to the therapeutic properties of music. In the modern world, with the commencement of using music as a therapy for wounded and survivors of World War II, India might have learned to elaborate the role of music beyond the purpose of entertainment, celebrations, and devotion.

With the establishment of Music Therapy programs at Michigan State University in the United States, India started to deal with this area of study. Music therapy organizations were established and have been spreading awareness among the people regarding this profession since then. The Center for Music Therapy Education and Research (CMTER), a unit of Mahatma Gandhi Medical College and Research Institute (Shri Balaji Vidyapeeth, Puducherry), developed the first university-based, one-year Post Graduate Diploma in music therapy, Master's degree in Medical Music Therapy, and Doctoral degree program in Music Therapy. Being a student of Indian classical music, the author herself was initiated in this field during her Master's degree. Through the readings of seminar proceedings, attending workshops and seminars on music therapy, having discussions with music professors and experts in music therapy, her interest grew stronger. With the keen interest to explore the reasons why and how music therapy works, the different ways to use music as therapy, the author started her study about this field. Therefore, to get a clear picture of the music therapy field and practices in India, people working as music therapists and music healers were searched and contacted. Due to the Covid pandemic, an online Google Form survey was shared with those 38 music therapists, and a telephonic interview was conducted with Dr. Nishindra Kinjalk ${ }^{1}$.

\section{Music Therapy Education and Training in India}

The music therapy field in India draws the interest of people from diverse educational backgrounds. It is foremost that practitioners of music therapy have knowledge of and familiarity with a wide variety of types of music. According to the American 
Music Therapy Association (AMTA) - "a professional music therapist holds a bachelor's degree or higher in music therapy from AMTA's approved college and university programs" (AMTA, 1998). The AMTA established guidelines for the education of professional music therapists in the United States, which include the learning of 3 main areas: musical foundations, clinical foundations, and music therapy foundations along with clinical training, and a supervised internship. After completing a degree in music therapy, therapists become "eligible to sit for the national board certification exam to obtain the credential Music Therapist - Board Certified (MT-BC), which is necessary for professional practice" (AMTA, 1998, $2^{\text {nd }}$ para.).

In this direction, Indian organizations such as Nada center for music therapy, Chennai school of music therapy, Music Therapy Trust, etc. have been offering certificate and diploma courses that are delivered online as well as offline. Offline courses offer either on-campus learning or distance learning for students with the help of study material, internships, lectures and training with experts, along with project works. Students pursue research work in music therapy to explore practical and theoretical aspects of music therapy. The Mahatma Gandhi Medical College and Research Institute (Shree Balaji Vidyapeeth, Puducherry) offers postgraduate diplomas, master's degrees, and doctoral degrees in Medical Music Therapy where students study the theory of music therapy and learn and practice its application in outpatient departments of the hospital, specialty rooms, and music therapy rooms of the hospital. They learn the application of music in various therapeutic settings with a diverse population (CMTER, 2021). The online survey conducted was helpful for understanding two important things about the educational background of music therapists in India. First, the majority of respondents either have certificates or diplomas as their educational qualification of music therapy (Fig.1). Along with the music therapy background, a large number of respondents have master's degrees as their highest qualification in different streams like Vedic astrology, divinity, Indian (Hindustani or Carnatic) classical vocal music, psychotherapy, counseling, psychology, communication, orthopedics, pediatrics, computer science, etc.; whereas some of them hold degrees in music, medicine, science, journalism, or philosophy, or hold doctorate degrees in their respective streams (Fig.2). Secondly, the survey found that a large number of therapists have earned their certificates or diplomas in music therapy either from Nada center for music therapy or from Chennai school of music therapy (Fig.3). The Chennai school of music therapy provides online-offline courses, along with an on-campus internship training of 750 hours at Mahatma Gandhi medical college and research institute, Puducherry, for candidates pursuing the Post-graduate Diploma in music therapy (PGDMT) (Sundar, 2012). With the facility of coursework and on-campus internship in a hospital in partnership with the center for music therapy education and research of Shri Balaji Vidyapeeth, Chennai school of music therapy has been providing professional training and certification in music therapy. Also, the Center for music therapy education and research has been providing diploma, graduate, post-graduate, and research degree programs in medical music therapy.

Dr. Kinjalk explained that the quality of education and professional standards in the field of music therapy in India needs many improvements. According to him, the "profession of music therapy in India is not all promising in present times, and needs authentic research works." Any kind of profession is based on the basic education and training in that field, and research helps to assess those dimensions, aspects, and fundamentals of educational and professional standards which facilitate the establishment of a field. Michael G. McGuire commented in one of his interviews with Dr. Sumathy Sundar that- "it is the knowledge, skills, and abilities that the person demonstrates that define the person's level of education, training, and professionalism" (Sundar, 2006).

Even though India has initiated the process to establish music therapy as a professional field, Dr. Kinjalk argues that there is not enough current research. By research, he is referring to scientific and experimental research which is required for any healthcare practice. Being a doctor, he understands that to validate any treatment, doctors need proof in the form of data, which can be assessed by experimentation. Similarly, to 


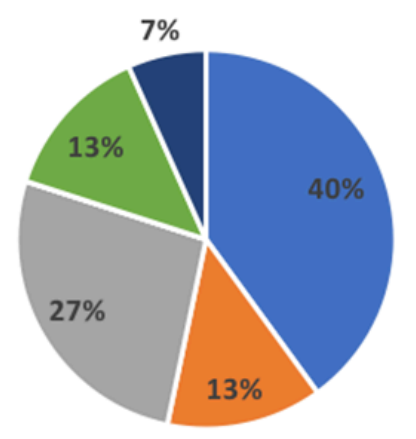

- Certificate in Music Therapy

- Diploma in Music Therapy

- PG Diploma in Music Therapy

॥ Graduate in Music Therapy

- Masters in Music Therapy

- Ph.D in Music Therapy

- Experience of 35 years in musical practice

Figure 1

Qualification in Music Therapy

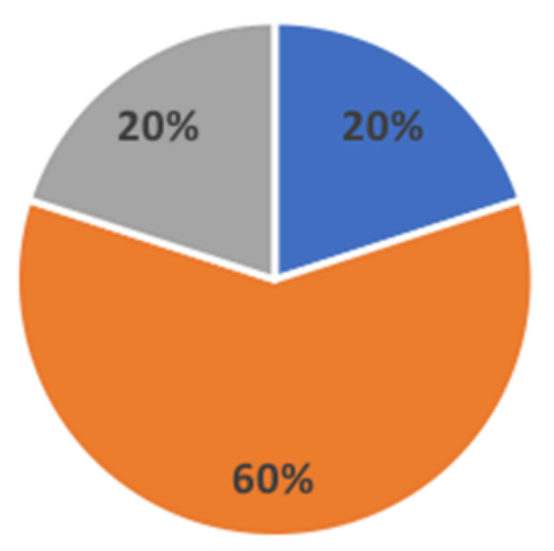

Bachelor's Degree

naster's Degree

- Doctorate

Figure 2

Educational Qualification of Music Therapists

prove a hypothesis of music therapy from an Indian perspective, therapists need data of improvement and effects which can be confirmed with scientific methods alone.

\section{Patients and Clients Visiting Music Therapists}

People with mild and severe psychological, emotional, and behavioral problems, can get benefits from music therapy interventions. The survey included both private practitioners and people working in hospitals and other therapy centers or clinics. It was found that most of the people visiting therapists suffer from anxiety, with the secondmost common health issue being depression (Fig.4). Less common reasons for visiting a music therapist (labelled "other" in Fig.4) include people with: death in the family or of near and dear ones; autism spectrum disorder; attention deficit hyperactivity disorder; schizophrenia; stress and psychosomatic disorders; alcohol or drug addiction; cancer or tumors; bipolar disorder; dementia; geriatric care; pregnancy-related issues; menopause; various neurological, neurosurgical and psychiatric conditions; pain management; and low self-esteem and self-confidence; as well as people pre-, during, or post-surgery. The greatest number of patients visiting therapists belong to the age 

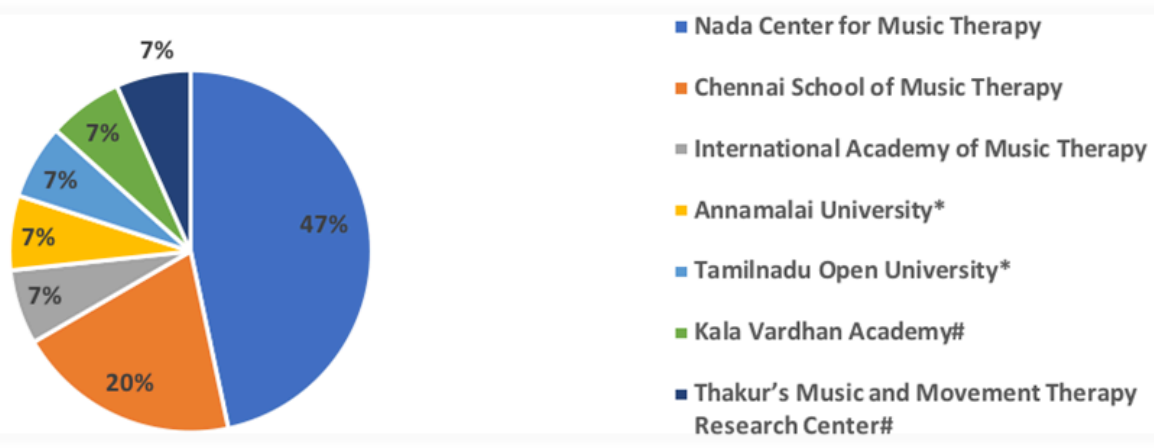

Note. *Through searching University Website, it has been found that there is no music therapy course/degree available at present. \#Respondents owned/initiated the academy/center.

Figure 3

Institution Where Earned Music Therapy Certificate/Diploma.

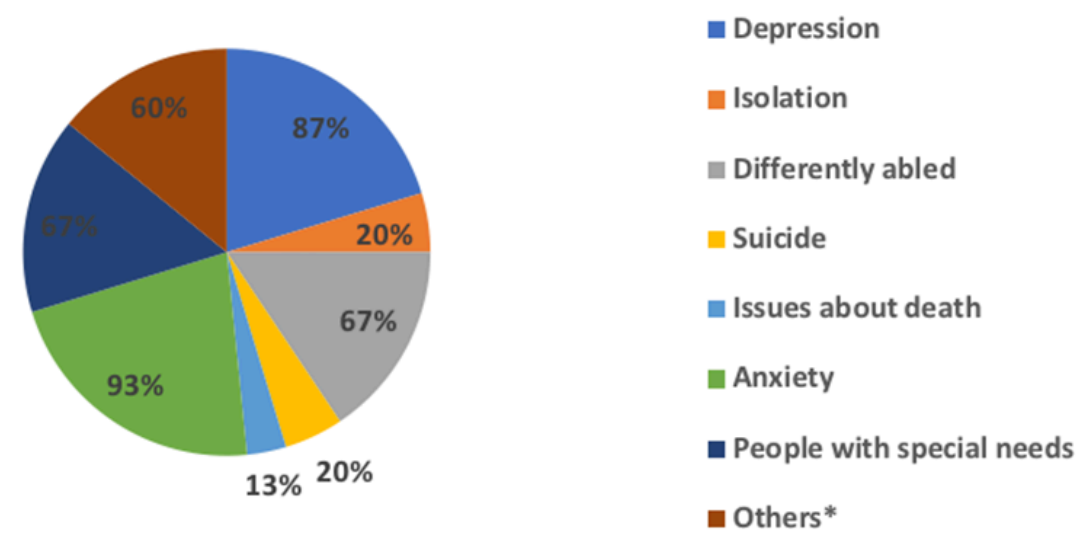

Note. *See list of "less common reasons for visiting a music therapist" found in main text.

Figure 4

Health Issues of Patients Visiting Music Therapists

group of 11-15 years, whereas the least number of patients visiting falls under the age group of 16-20 years (Fig.5).

\section{Indian Music Therapists and Their Work Experience}

As per the responses recorded in the survey, less than half of the respondents belong to the age group of 31-40 years, while approximately one-fourth are in the age group of 41-50 years (Fig.6). When looking at the gender ratio between males and females in this profession, $60 \%$ are females while $40 \%$ of practicing therapists are male. As for the total work experience as a music therapist, half of the respondents have work experience of 0-5 years, while only a few of them have $21+$ years of experience as a music therapist (Fig.7). The majority of respondents are practicing music therapy as their primary profession, while few are practicing this profession as a secondary option, or they are involved in music therapy practices along with their primary professions such as Carnatic music teacher, orthopedic surgeon, pediatric allergist, consultant orthopedic surgeon, and associate professor (Fig.8). Another important thing that came to light with the help of this survey was that more than half of the therapists reside in the Southern and South-Eastern part of India (Fig.9). 


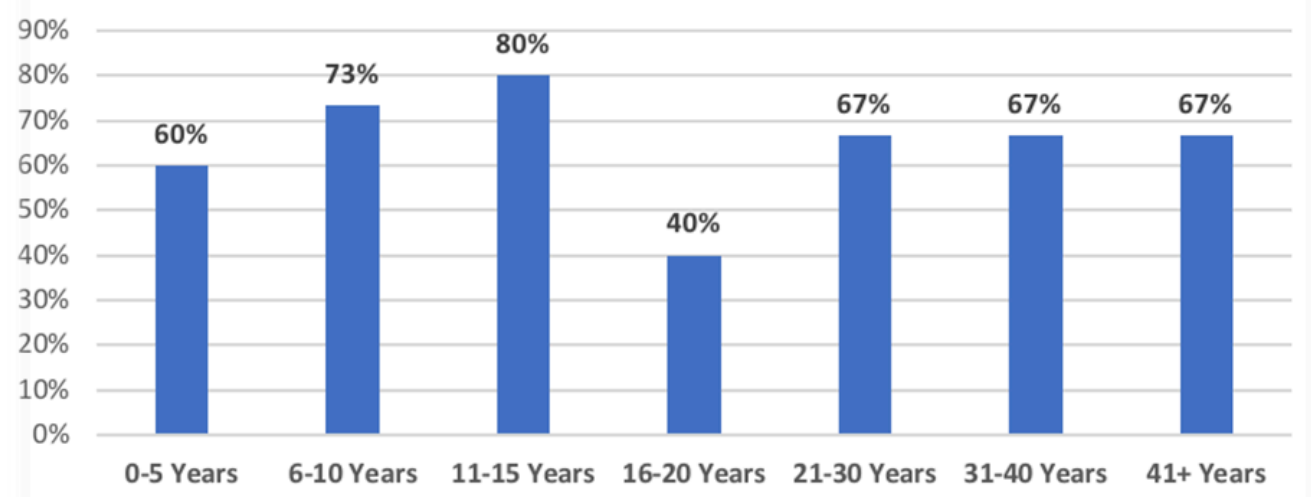

Figure 5

Age Group of Patients

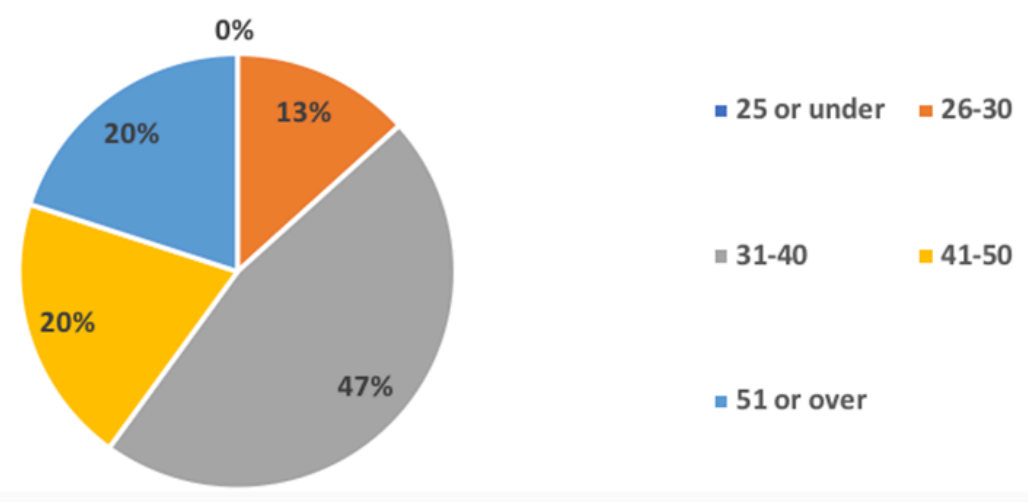

Figure 6

Age Group of Music Therapists

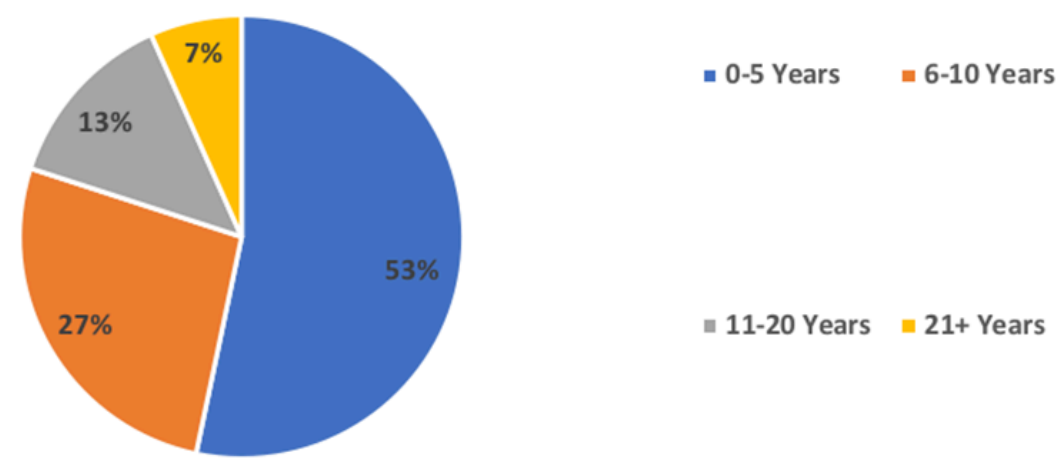

Figure 7

Work Experience of Music Therapists

\section{Music Therapy Research and Literature}

Many claims were found in the history of Indian music about how music affected its listeners and performers. One claim was about famous Dhrupad singer Tansen who could light up lamps with his spectacular presentation of Raga Deepak (the raga of fire) and could give relief from the intense heat generated by raga Deepak by singing the ra- 

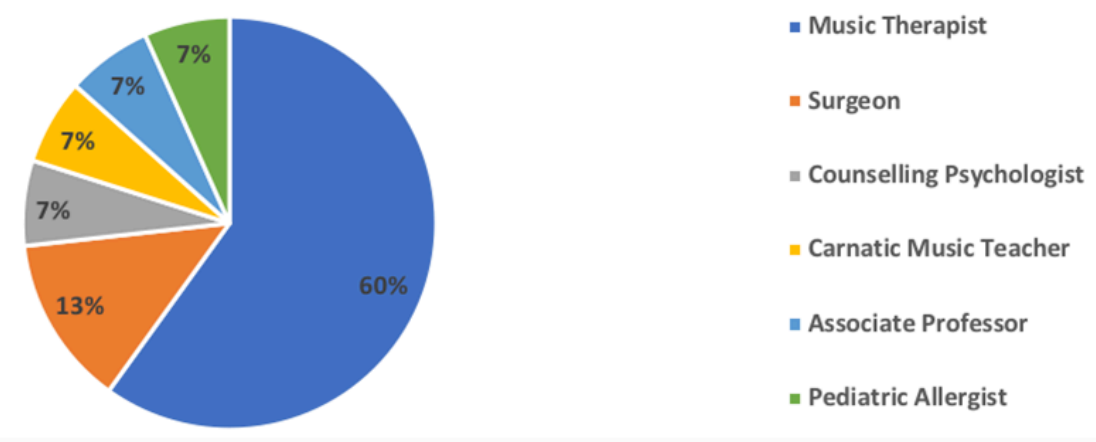

Figure 8

Primary Profession of Music Therapists

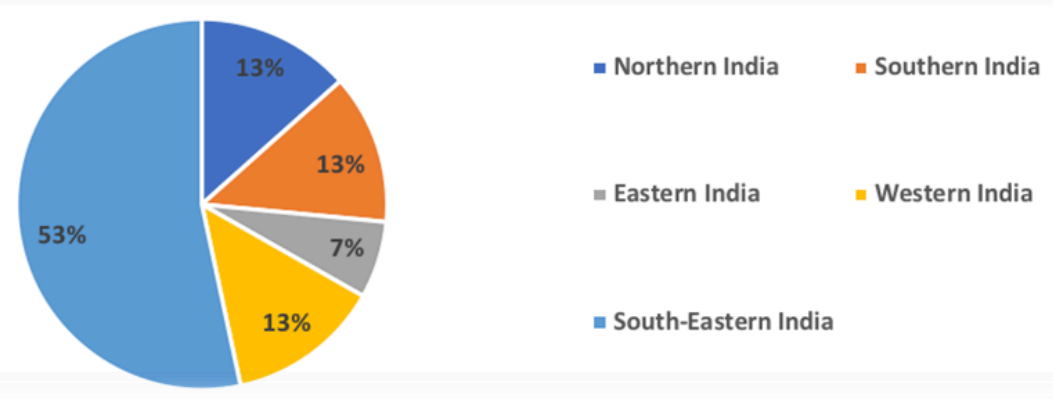

Figure 9

Work Location of Music Therapists

ga Megh Malhar (the raga of rain). Another famous claim is about Pandit Omkarnath Thakur of Gwalior Gharana who was supposed to have cured Benito Mussolini of insomnia while on a trip to Italy. Also, the legendary singer is believed to have performed Raga Kafi to calm down a ferocious lion in a Kabul Zoo. References are found in the $12^{\text {th }}$ to $14^{\text {th }}$ century about Jayadeva, NarayanaTirtha, Annamacharya, and others who have brought a deceased person to life through their music. As per Rammohan (2017), MuthuswamiDikshitar has composed a song Brihaspate in RagaAttana to cure his student's stomach ailment (Rammohan, 2017). But from a research point of view, without scientific proof, authentic data, and documentation, these are acceptable only as claims with potential for further research.

Dr. Kinjalk addressed the present condition of research and literature in India with much criticism. He said that - "except for few old stories, popular anecdotes, and hypothesis, there is hardly any music therapy literature in India." He further emphasized the need for authentic and evidence-based research. He mentioned that available literature consisting of voluminous theses for Ph.D. and M.Phil. at various universities, and observation-based research papers do not form a sufficient evidence base. As per the survey, respondents affirmed that there is a lack of experiment-based research literature in India, which impacts this field in our country.

\section{Popular Music Therapy Models and Methods in India}

Before moving further into this section, it is very important to build a basic understanding of the core terminologies of music therapy like model, method, technique, procedure and intervention. Though people use these terms as interchangeable to each other, it is important to recognize that they represent different contexts of music ther- 
apy. Maranto (1981) recognized 14 models or schools of music therapy in the USA alone, and more than 100 different techniques, which he documented in his book Music Therapy: International Perspectives (Wigram, Pedersen, \& Bonde, 2002). Bruscia (1998) defined these core terms in his book The Dynamics of Music Psychotherapy as following:

a method is here defined as a particular type of music experience that the client engages in for therapeutic purposes; a variation is a particular way in which that music experience is designed; a procedure is everything that the therapist has to do to engage the client in that experience; a technique is one step within the procedure that a therapist uses to shape the client's immediate experience; and a model is a systematic and unique approach to method, procedure, and technique based on certain principles. (Bruscia, 1998, as cited in Wigram, Pedersen, \& Bonde, 2002, p.113)

The $9^{\text {th }}$ World Congress of Music Therapy in Washington presented 'five internationally known models of music therapy' as a concurrent theme, which were introduced and illustrated from different perspective (Wigram, Pedersen, \& Bonde, 2002). Those models of music therapy were:

i. Guided Imagery and Music developed by Helen Bonny (also known as Bonny Model)

ii. Analytical Music Therapy developed by Mary Priestley (also known as Priestley Model)

iii. Creative Music Therapy developed by Paul Nordoff and Clive Robbins (also known as Nordoff-Robbins Model)

iv. Benenzon Music Therapy developed by Rolando Benenzon

v. Behavioral Music Therapy developed by Clifford K. Madsen

Behavioral music therapy was found to be the most popular among music therapists in India (Fig.10). Some of the respondents mentioned a few new concepts such as Indian music therapy, classical music techniques for meditation, the Carnatic Raga-based Nada Anusandhan method, etc. It should be noted that little or no references have been found about these terms, except for Nada Anusandhan which has been mentioned in only a few published papers (without any background, origin, or philosophy of this method) and lectures of some Indian spiritual gurus (Gurumaa, 2013)(Fig.11). Introducing KIMMA in 1987, Dr. Kinjalk's current approach to implementing this method is based upon decades of research and experiments, and since then he has been using this method with his patients.

When asked about popular music therapy models, Dr. Kinjalk's response was quite thought-provoking that - "these models have been available to us for a few years now, in the same form or certain modified form. Even though, we were not able to address the vital issues of uniformity of music in clinical application." According to him, these 5 popular models (mentioned above) of music therapy have scientific techniques but they are lacking in the process of defining which genre of music is useful for a particular condition. He further mentioned that even after the best scientific backup in the world, these methods could not become part of popular and modern medical practice.

Dr. Kinjalk explained with great detail that "KIMMA involves 3Ms: Man, Music, and Match. It was identified that there is music which affects a man's mood and lowers the stress levels and ultimately overall effect on person's ailment, but the missing link of 'match' was identified by this technique" (Kinjalk \& Kinjalk, 2019, p. 30). In this technique of music therapy, a team of an expert musician and doctor assesses the patient's history in the first place. After the complete assessment and review process, they match the music to the patient's suitability, a process that is informed by years of research. Dr. Kinjalk clarified that not every type of music, be it raga, western music, instrumental, or any song, can be helpful to all types of patients. A review of the patient's history helps to identify different factors deciding the taste in music for a particular person. After that, selective therapy based on the history review is prescribed along with the 


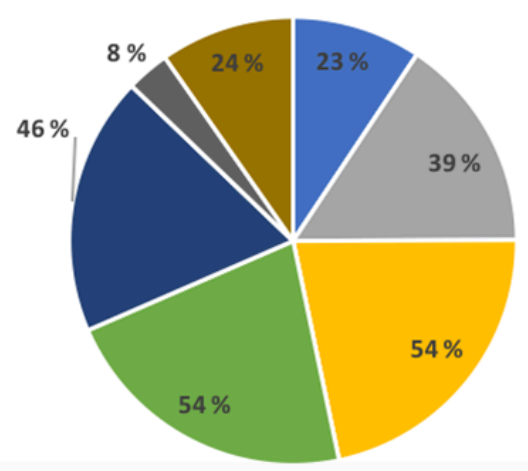

- Guided Imagery \& Music (Bonny Model)

- Analytically Oriented MT (Priestley Model)

= Creative MT (Nordoff-Robbins Model)

= Behavioural MT

- KIMMA

- Community MT

- Neurologic MT

- Kodaly

- Indian Music Therapy

- Others*

Note. "Includes "Not available," "don't know," "don’t have a standardized model in India yet."

Figure 10

Music Therapy Models Popular Among Indian Music Therapists

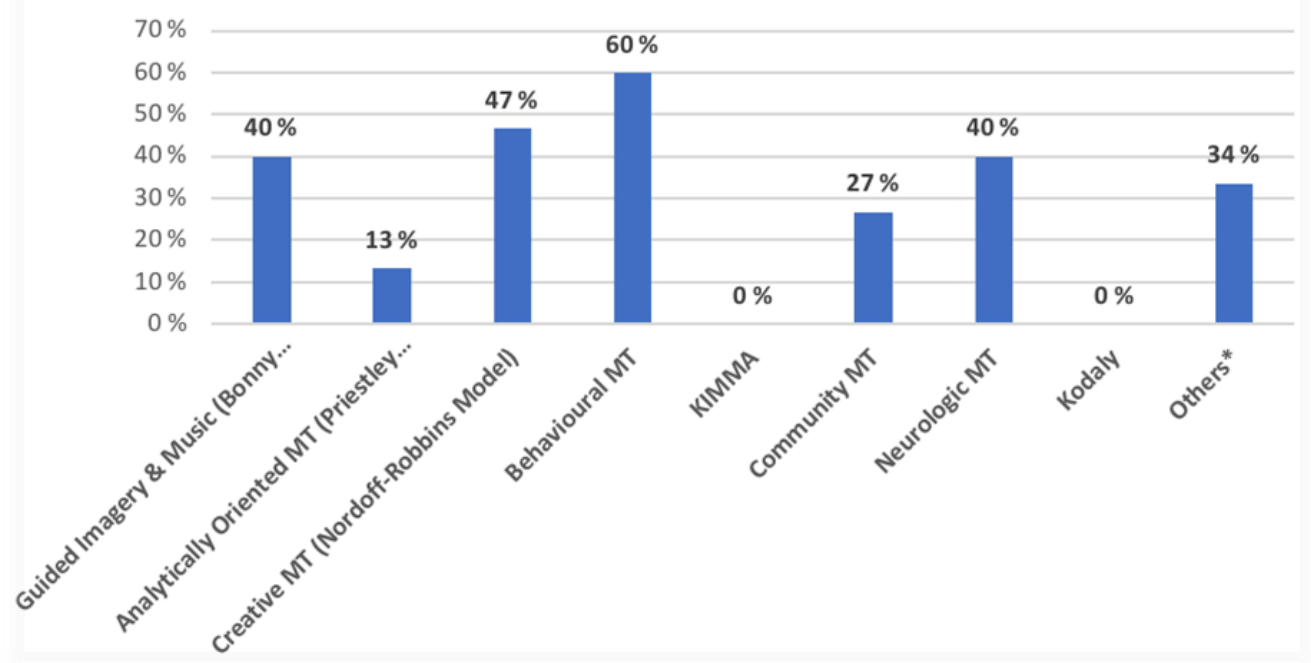

Note. *Little or no references have been found for these terms.

Figure 11

Music Therapy Models Applied by Music Therapists in India

medicine. It is worth mentioning that the medicine is not omitted but the dose is gradually reduced, as per the improvements seen during the treatment (Kinjalk N. , 2020).

KIMMA is a technique developed in India, but it is not popular among the music therapy fraternity as concluded from the responses recorded in the survey. While very few of them were familiar with this technique, more than half of the respondents had never heard about KIMMA (Fig.12).

When talking about interventions and procedures, it was identified that music therapy includes active involvement in various musical activities like singing, improvising, playing an instrument, and lyric writing; as well as passive activities of passive music listening, and relaxing with music. Professor Suzanne Hanser of Berklee College of Music said that music therapy serves five significant purposes (Chowdhury, 2019) which include:

1. Shifting one's attention from problems to a solution

2. Offering a rhythmic structure for relaxation and breathing 


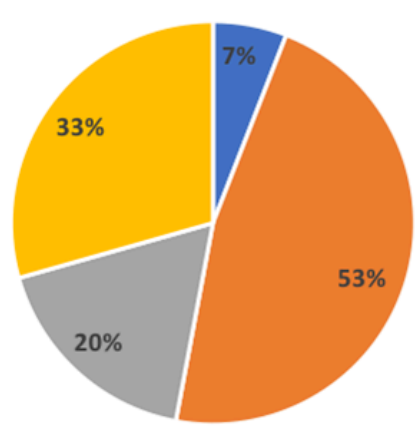

- Familiar

- Unfamiliar

- No Response

Ether India Music Therapy Techniques*

Note. *Include Practice and use of their own methods, Raga Therapy, Raga Improvisational Relaxation Music, Vedic Chants, Sound Bath, Earworms.

Figure 12

Music Therapists Familiar with KIMMA

3. Helping clients visualize positive imagery that evokes pleasure and happiness

4. Helping them achieve a deep state of relaxation

5. Changing mood

However, participation in musical activities is only half of the complete picture. Therapists need to plan the complete session which includes the objective of therapy, selection of music, assessment process, and techniques to apply for maximum involvement and results.

- Objectives and Goal of Music Therapy: From the objective, we understand the step-by-step outcomes or improvements in every single session of music therapy intervention. While the goal is the final and ultimate result of music therapy treatment (Berger, 2009), it also informs which objectives can be used to track progress towards the goal. These two concepts motivate the procedure and techniques of music therapy. Respondents of the survey favored emotional quotient as well as cognitive issues over intelligence quotient, and other variables as the objectives and goals of their music therapy interventions (Fig.13). Dr. Kinjalk, in the perspective of KIMMA and every other music therapy approach, mentioned that the objectives and goals of music therapy are individual to each client. He focuses on the management of the patient's health issues where music therapy supports as an additional tool. He emphasized that KIMMA does not promise relief from the patient's disease, but with proper use, it can certainly augment the clinical or therapeutic outcomes.

- Musical Preferences: It is deduced through the survey that Hindustani music (North Indian classical music) and Carnatic music (South Indian classical music) are both popular among music therapists based on patient's preferences (Fig.14). Genres such as Vedic chants, light music, Bhajan, Ghazal, folk music received fewer responses which show less popularity. Dr. Kinjalk explained that he focuses on the taste and preferences of the patient while selecting appropriate music for the session.

- Assessment and Evaluation Process: As per the survey, the majority of therapists report interviewing their client before and after each music therapy session, and observing the client during the sessions. On the other hand, evaluation and assessment with the help of psychological tests are less popular among music therapists, which received the least number of responses that show little knowledge of such tests among music therapists in India (Fig.15). On the contrary, Dr. Kinjalk assesses his clients over time, as their health situation develops. In his 


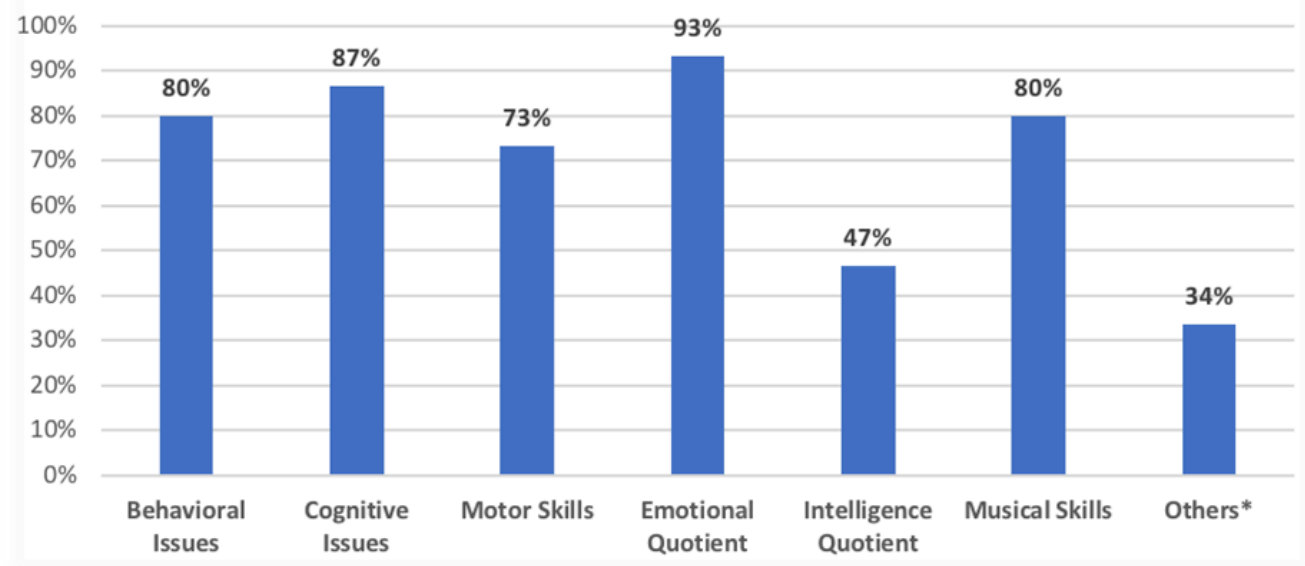

Note. *Includes "relaxation," "detox," "objectively measured stress," "psychological issues \& life challenges, based on patient's need," "expressive language \& related disorders," etc.

Figure 13

Objectives and Goals of Music Therapy
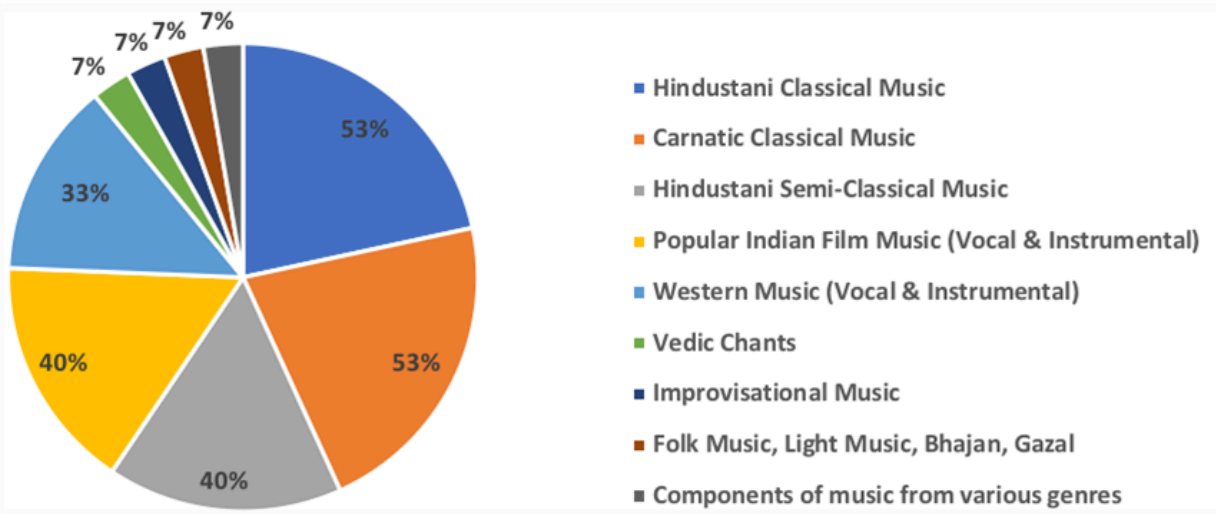

Figure 14

Musical Preference

explanation, Dr. Kinjalk said that since 1996, his institute has been using Indian forms of music to help patients with stress-related disorders, hypertension, diabetes, depression, insomnia, anxiety, learning difficulties, and Alzheimer-like ailments. Although KIMMA music therapy does not replace the medicines his patients receive, according to Dr. Kinjalk this method may provide fast relief from the symptoms of pain, anxiety and depression for those suffering from cancer, HIV, hypertension, anxiety, and depression.

Music therapy is all about involvement, participation, compassion, being open and comfortable for the client as well as the therapist. Dr. Kinjalk mentioned that - "it cannot be said that music did not work for patient, but the question should be to what degree did the music therapist make the music work for the patient?" He further said that prescribing music therapy is an art to be imbibed and learned (Kinjalk \& Kinjalk, 2019). Research studies support the positive satisfaction levels of patients who participated in music therapy interventions in various settings. In the current survey, therapists responded that the majority of their clients gave a positive response about the music therapy treatment and were highly satisfied (Fig.16). At the same time, therapist respondents reported no negative response in terms of client satisfaction. 


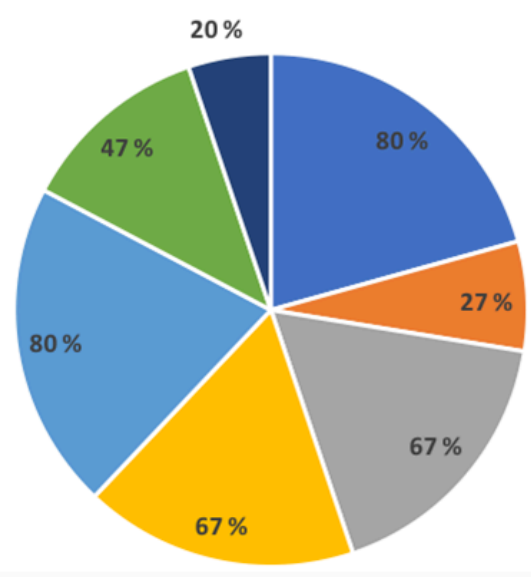

- Interview of the client before and after each music therapy session

- Psychological Test of client at the beginning and in the end of complete music therapy session

- Interview of the client at regular intervals throughout the course of music therapy

- Interview of client's family members and friends at the beginning and in the end of complete music therapy session

- Obsenvations of the therapist during the sessions

- Assessment of client's musical performance

- Others*

Note. "Includes "an interview with another medical professional working with the client," "case history," "both scale assessment and interview with the guardian," and "comprehensive periodic assessment by the institute/school."

Figure 15

Assessment and Evaluation Process

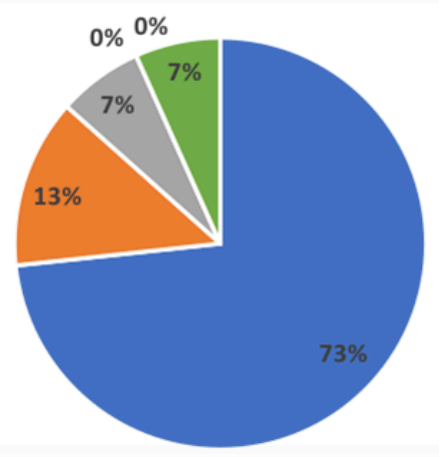

\author{
- Highly Satisfied \\ - Moderately Satisfied \\ - Neutral \\ " Not Satisfied \\ - Highly Dissatisfied \\ - Depends on the session
}

Figure 16

Satisfaction Among Patients

\title{
Collaborations with Other Professionals during Music Therapy Sessions
}

Music therapists collaborate with other professionals to assess their clients and case, a practice that can be more beneficial for clients. Research studies support the idea of interdisciplinary and transdisciplinary collaboration among music therapists and other professionals (Arns \& Thompson, 2019; Boswell-Burns, 2016; Robinson, 2015; ). The primary objective to participate in such collaborative practices is to provide a better service to the patient or client during the music therapy intervention. In their research study, Boswell-Burns (2016) identified that music therapists collaborated most frequently with occupational therapists, speech therapists, and medical staff, and least frequently with a massage therapist. As per the survey, respondents collaborated most frequently with counseling psychologists, medical doctors, clinical psychologists, professional musicians, and instrumentalists. On the other hand, respondents in the survey collaborated least frequently with art teachers, creative art therapists, etc. (Fig.17).

Dr. Kinjalk mentioned collaborating with his fellow doctors and other hospital staff during the treatment of patients. These collaborations also include further national and international research studies such as music therapy's multi-centric trials on patients 


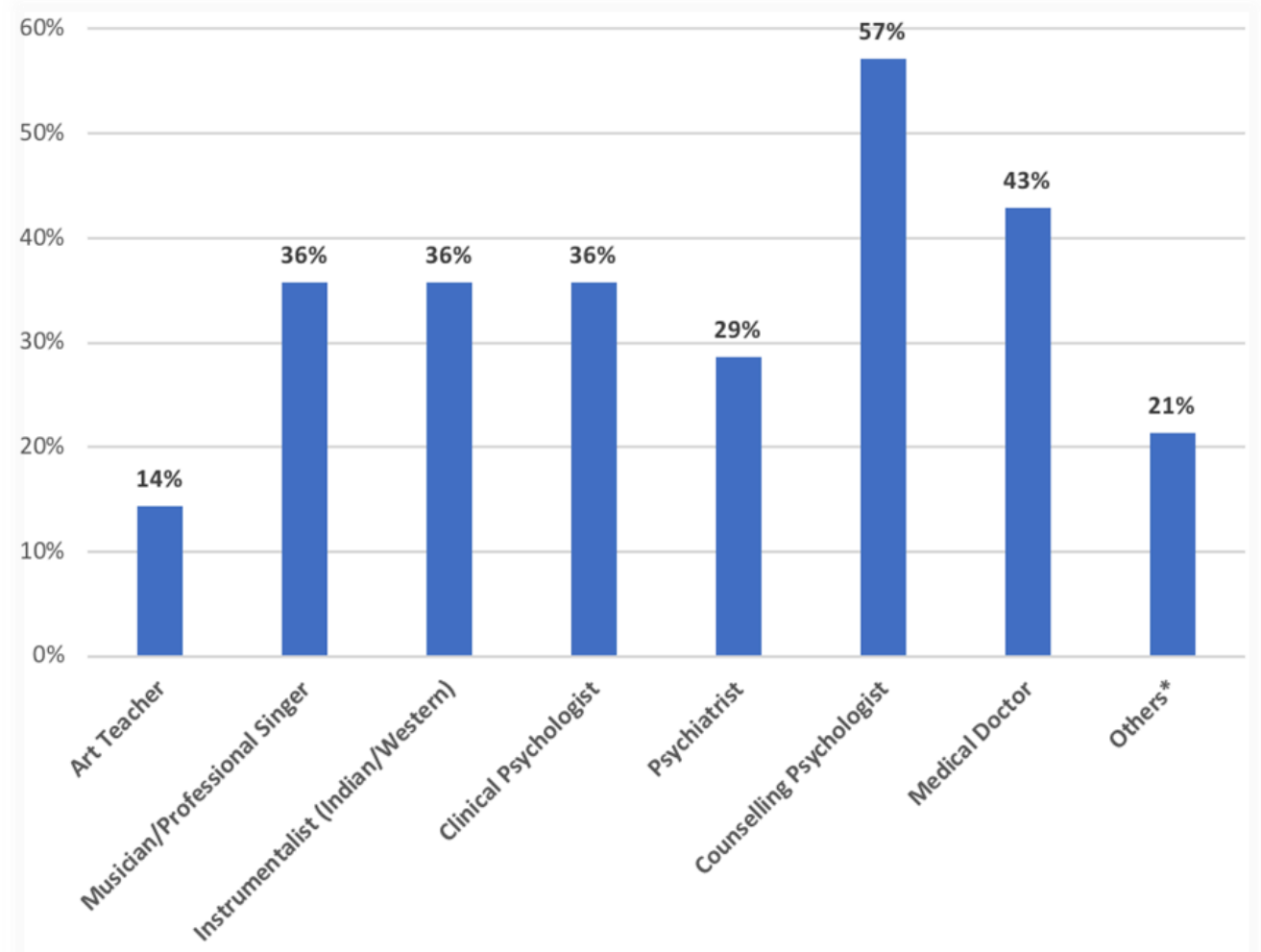

Note. "Includes "Tabla player," "creative art therapists," "interventionists at school/institute"

Figure 17

Collaboration with Other Professionals

and into biomolecular system (relating to 'biomolecule' which means an organic molecule, such as protein, carbohydrates, lipids, or nucleic acid, present in living organisms).

\section{Current Status of Music Therapy in India and Potential Barriers for Expansion}

The motivational force to establish music therapy as a profession in Western countries was World War II in 1943. The US army provided music programs as a recreation service to the wounded soldiers of their army, which eventually necessitated the establishment of systematically implemented and evaluated therapeutic use of music. It is well known that the outcomes were positive for those music programs (Gooding \& Langston, 2019). But even then, the programs were not called music therapy because the music was provided to the service members only as a medium to motivate, stimulate, build morale, and entertain. By the mid-1940s, studies supporting the application of music as therapy served as critical pieces of scientific evidence that provided support for the development of music therapy education programs in the United States. Thereafter, the Certification Board for Music Therapists was established around 1983 (CBMT, 2021). By the 1990s, the profession of music therapy was established all around the world, including in India. In India, organizations namely the Center for music therapy education and research, Chennai school of music therapy, Nada center for music therapy, and the Indian association of music therapy have been providing professional training, certificate, diploma, graduate, post-graduate, and research degree courses in music therapy.

Survey respondents perceive those developments in the field of music therapy are good, and some respondents report that research studies conducted in India are scientifically sound (Fig.18). These findings are in contrast to the way in which Dr. Kinjalk 


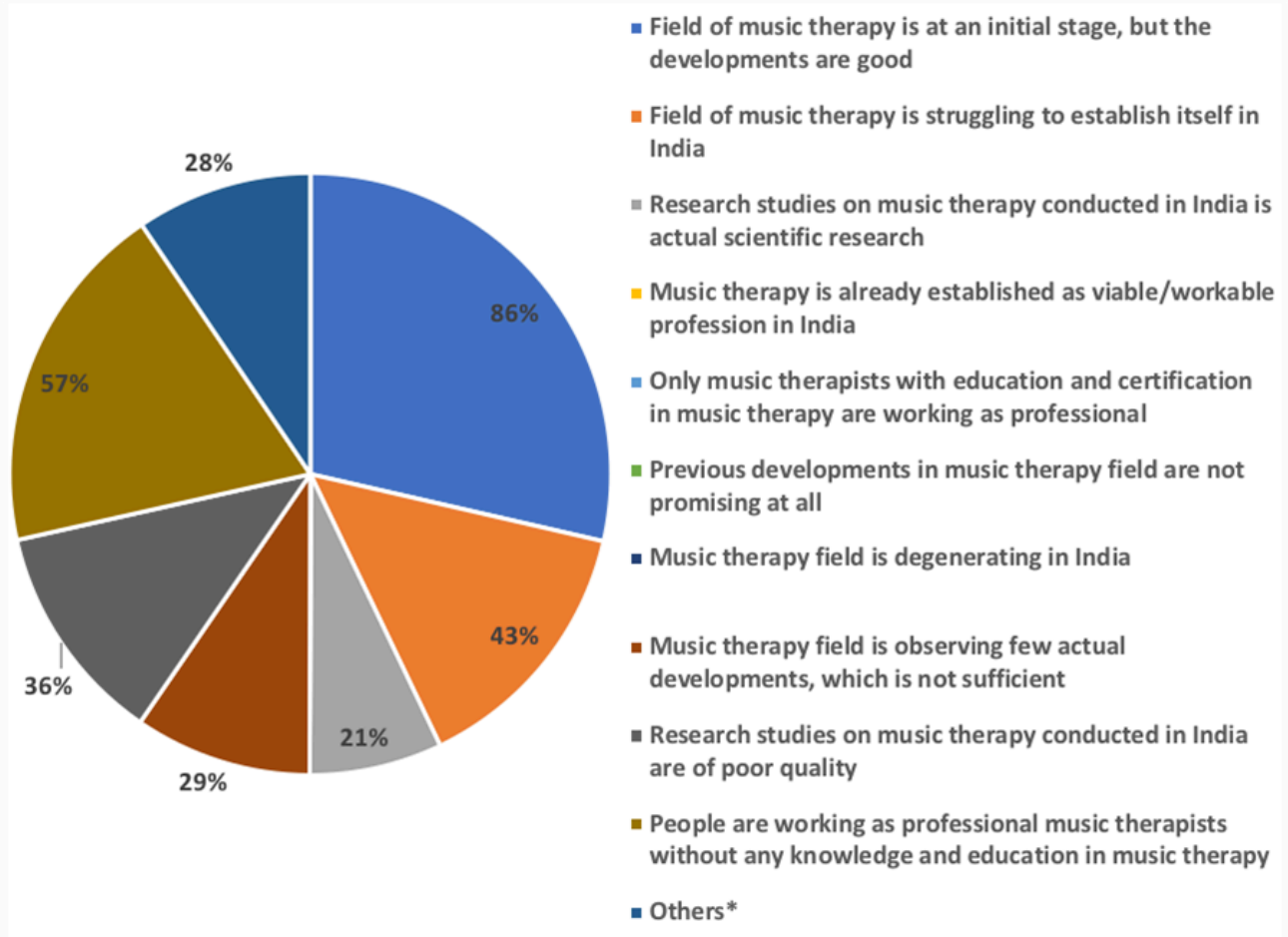

Note. "Includes "open-ended answers"; "lack of standardized training method"; "Indian music therapy will take time to develop because of the vastness, spirituality, and abstractness in Indian music"; "music therapy in India is taking longer time due to the varied cultural and musical orientations of India."

Figure 18

Current Status of Music Therapy in India

put forward negative views of the research studies conducted in India. According to Dr. Kinjalk, studies conducted in India are of poor quality, and the music therapy profession is not in a promising condition at all.

Music therapy has not received much attention in India as compared to the west. India is still behind in this pursuit of establishing the music therapy profession, despite the rich musical traditions of both Indian and Carnatic classical music (Singh, Chandra, \& Chakraborty, 2018). As for the reported use of music's therapeutic properties, there are fewer research studies examining the effect of using music as a therapeutic tool in India than in the west. There is documentation of using music as a form of treatment in 1855 to calm down excited patients in the lunatic asylum of Dacca or Dhaka (of the Indian subcontinent), now part of Bangladesh. It is one example of the historical use of music in hospitals for the treatment of patients (Sharma, 2004).

In the survey, it was made clear by the respondents that the expansion of music therapy in India is negatively affected by the lack of standard education, lack of interest in scientific learning among the students, and lack of experiment-based research literature in the country (Fig.19). Some respondents reported that the mindset of music therapy practitioners is also a factor.

\section{Summary}

The purpose of this paper was to explore current music therapy practices in India, how much we have achieved in the last four decades, and what the developments of that journey are. Not only was the survey helpful to record the dimensions of music therapy practices, but it was also helpful in building a rough picture of current practices. People who have been practicing music therapy, or using music as a therapeutic tool along 


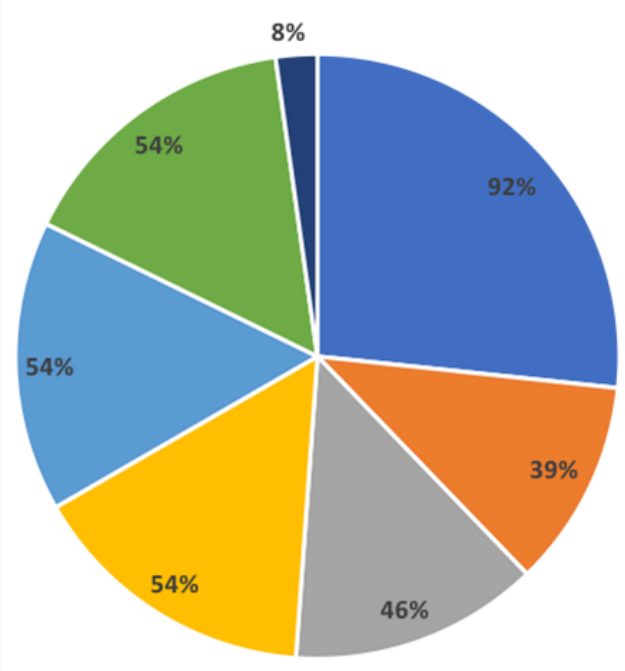

- Lack of standard education in Music Therapy

- Lack of advocacy for Music Therapy

- Less/no scope for career in Music Therapy

= Less/no research of music therapy in Indian perspective

- Lack of/no interest for scientific learning among the students of traditional music learning

- Lack of/no experiment-based research

literature in country

- Mindset of Music Therapy Practitioners

Figure 19

Barriers for Expansion of Music Therapy in India

with other therapies are now being considered as a dimension of music therapy itself. In the big picture of music therapy practices, the standard education and professional certification of music therapists in India is a major point that needs focus as standard education in any field decides the future of that area, whether it is art, science, or any other professional field. The rest of the dimensions like research, training, career, and future of respective fields depends upon the development of standards for guiding education of music therapists. After education, another major point that needs focus is advocating for scientific research in this field. Doctors have considered music therapy as a form of complementary and alternative medicine in many countries now, but India is lagging in this direction. Experiment-based research studies should be promoted to support the claims and observations about the healing properties of various genres in Indian music. Such research studies and scientific literature will further support and promote the methods and interventions in music therapy suitable from the Indian perspective.

Attention towards the two major aspects of music therapy, i.e., education and research, will help build this area into a strong profession soon. Attempts, either small or big, should be put in the right direction.

Music therapy is a field with huge opportunities for people from different backgrounds, but it needs a strong foundation in our country where scholars and learners can receive guidance and motivation for future projects. Otherwise, in the words of Dr. Kinjalk, "with so much of internet around, and careless approach of our policymakers at different levels, I am concerned for the future of music therapy in India in next 10 years. We are at a crossroads. If we take this issue seriously, we can be the leaders in the world, and if not, then we shall see this slipping from our hands." The field of music therapy in India can thrive further with appropriate policies from the authorities, more universities offering courses in music therapy up to the Doctoral level, and conducting scientific research studies to offer an authentic basis for theories of music therapy.

\section{About the Author}

Dr. Priyanka, Ph.D. in Hindustani Music, is a learner, explorer, teacher and music lover. With a background of Hindustani vocal music, she has done her Masters in Hindustani Classical Music (Vocal). She completed her Ph.D. in music therapy under the guidance of Dr. Mallika Banerjee from Indira Gandhi National Open University (IG- 
NOU) in 2021. Her research work in music therapy with Indian Raag Yaman motivated her to explore various aspects of this field. Her papers on music therapy have been published in Indian journals of music. Currently, she is working as a trained IB PYP music teacher in school.

\section{Notes}

1. Dr. Nishindra Kinjalk consented to be interviewed virtually. He has read and approved of the quotations used in this paper.

\section{References}

Adimulam, M. (n.d.). Other therapy. Retrieved November 28, 2020, from https://www.asap.org.in/other-therapy

Algoodkar, S., \& Sunitha, G. (2019). Impact of music therapy in reducing the severity of depression measured by MADRS among depression patients: A randomized control trial. International Archives of Integrated Medicine, 6(1), 41-47.

AMTA. (1998). Professional requirements for music therapists. Retrieved October 2020, from https://www.musictherapy.org/about/requirements/

Arns, B., \& Thompson, G. A. (2019). Music therapy teaming and learning: How transdisciplinary experience shapes practice in a specialist school for students with autism. Australian Journal of Music Therapy, 30, 1-21. Retrieved December 2020, from https://www.researchgate.net/publication/332865428

Banerjee, A., Shankha, S., Sengupta, R., \& Ghosh, D. (2015, September 29). Music and its effect on body, brain/mind: A study on Indian perspective by neurophysical approach. Insights in Blood Pressure, 1(1), 1-11. Retrieved November 29, 2020, from https://bloodpressure.imedpub.com/archive.php

Bansal, P., Kharod, U., Patel, P., Sanwatsarkar, S., Patel, H., \& Kamat, H. (2010, August). The effect of music therapy on sedative requirements and haemodynamic parameters in patients under spinal anaesthesia: A prospective study. Journal of Clinical and Diagnostic Research, 4(4), 2782-2787. Retrieved November 28, 2020, from https://www.jcdr.net/ article_fulltext.asp?id $=833$

Berger, D. S. (2009, March 1). On developing music therapy goals and objectives. Voices: A World Forum for Music Therapy, 9(1). https://doi.org/10.15845/voices.v9i1.362

Bharathi, G., Venugopal, A., \& Vellingiri, B. (2019, June 25). Music therapy as a therapeutic tool in improving the social skills of autistic children. The Egyptian Journal of Neurology, Psychiatry and Neurosurgery, 55(44), 1-6. https://doi.org/10.1186/s41983-019-0091-x

Bhowmick, A. (2019, February 2). Healing music. Retrieved November 28, 2020, from https://www.ckbhospital.com/news-updates/healing-music/

Boswell-Burns, A. M. (2016). Interprofessional collaboration across the treatment process in music therapy (Order No. 10120183). Available from ProQuest One Academic. (1795570265). https://www.proquest.com/dissertations-theses/interprofessionalcollaboration-across-treatment/docview/1795570265/se-2 accountid $=8579$

CBMT. (2021, October 18). About CBMT. Retrieved from https://www.cbmt.org/about/

Chowdhury, M. R. (2019, October). 15 Music therapy activities and tools. Retrieved December 15, 2020, from https://positivepsychology.com/music-therapy-activities-tools/

Gooding, L. F., \& Langston, D. G. (2019, November 7). Music therapy with military populations: A scoping review. Journal of Music Therapy, 56(4), 315-347. https://doi.org/ 10.1093/jmt/thz010

Gurumaa, A. (2013). What is naad anusandhan? (Youtube, Compiler) India. Retrieved November 2020, from https://www.youtube.com/watch?v=WdYA3B9Exbg 
Handbook-Shri Balaji Vidyapeeth. (n.d.). Retrieved August 16, 2021, from https://drive.google.com/file/d/ 0B93y49fK56SLQ3FYT0UwM0hSSXRyN2p4ZTNvQms4dWNfd3dJ/ view?resourcekey=0-Obxo90DBZOpbHIKVWmrjjw

Hegde, D. S. (2020, May 19). Music cognition laboratory. Retrieved January 8, 2021, from https://nimhans.ac.in/neurobiology-research-centre-nrc/music-cognition-laboratory-nrc/

IHIF. (2016, June 21). Music therapy at IHIF rehabiltation centre Delhi. Retrieved November 28, 2020, from https://indianheadinjuryfoundation.org/music-therapy-at-ihif-rehab-centredelhi/

Indira, A., Pydimarry, P. V., Katari, K., Hemanathan, R., Pal, R., Ghosh, A., ... Agrawal, A. (2018, December 24). Effectiveness of music therapy on academic performance of nursing students. International Journal of Academic Medicine, 4(3), 278-283. Retrieved January 8, 2021, from http://www.ijam-web.org/text.asp?2018/4/3/278/248329

Kar, S. K., Ganguly, T., Roy, S. S., \& Goswami, A. (2015, March 25). Effect of Indian classical music (raga therapy) on fentanyl, vecuronium, propofol requirements and cortisol levels in cardiopulmonary bypass. Journal of Anesthesia \& Critical Care, 2(2), 1-5. https://doi.org/ 10.15406/jaccoa.2015.02.00047

Kinjalk, D. N., \& Kinjalk, D. M. (2019, December). Music therapy: Emerging catalyst in the west are we ready to prescribe it? International Journal of Scientifc Research, 8(12), 30. https://doi.org/10.36106/ijsr

Kinjalk, N. (2020, September 14). Music therapy and KIMMA. (Priyanka, Interviewer)

Krishnaswami, P., \& Nair, S. (2016). Effect of music therapy on pain and anxiety levels of cancer patients: A pilot study. Indian Journal of Palliative Care, 22(3), 307-311. Retrieved January 8, 2021, from http://www.jpalliativecare.com/text.asp?2016/22/3/307/185042

Lakshmi, P. L., \& Sharma, D. B. (2015, October). A study to assess the effectiveness of music therapy on hypertensive elderly residing in selected geriatric homes, kancheepuram district, tamilnadu, India. International Journal of Scientific Research, 4(10), 462-464. Retrieved November 30, 2020, from https://www.researchgate.net/publication/ 324719453_A_STUDY_TO_ASSESS_THE_EFFECTIVENESS_OF _MUSIC_THERAPY_ON_HYPERTENSIVE_ELDERLY_RESIDING_ IN_SELECTED_GERIATRIC_HOMES_KANCHEEPURAM_DISTRICT_TAMIL_NADU_INDIA

Mahendran, M., \& Jagdeesan, D. T. (2017, September). Effcetiveness of active and passive participation in music therapy on social emotional skills of ADHD children. International Journal of Science and Research, 6(9), 1093-1098.

Maranto, C. D. (1981). Ethics in music therapy: A programmed text. Ethics in music therapy: A programmed text, 1-370. LSU Historical Dissertations and Theses, 3607.

https://digitalcommons.1su.edu/gradschool_disstheses/3607

Mythily, D. T. (2010, May). Music therapy for cardiac rehab. Retrieved January 8, 2021, from http://apollopharmacy.apollolife.com/articles/ Heart_\%20Music\%20Therapy\%20for\%20Cardiac\%20Rehab.aspx

Pai, V. (n.d.). Tamahar programs for children with special needs. Retrieved November 28, 2020, http://www.tamahar.org/programs.html

Paul, V. K., Gupta, A., Singh, M., Deorari, A. J., \& Pandey, R. M. (1999, April 1). Effect of Indian classical music on heart rate and oxygen saturation in preterm neonates in the ICN. Pediatric Research, 45(16), 1-4. https://doi.org/10.1203/00006450-199904020-00104

Rammohan, V. G. (2017). Music therapy: The present scenario. In M. V. Raju, \& M. V. Raju (Ed.), Health, Psychology and Counselling (pp. 103-115). New Delhi, India: Discovery Publishing House.

Ravi, M. (n.d.). Programs. Retrieved November 28, 2020, from http://www.meeramusictherapy.org/programs 
Robinson, A. S. (2015). Interdisciplinary collaboration with music therapy during routine pediatric dental procedures. Master's Thesis, 1-95. Lexington, Kentucky, USA: University of Kentucky. Retrieved December 2020, from http://uknowledge.uky.edu/cgi/

viewcontent.cgi ?article $=1042 \&$ context $=$ music_etds

Sharma, S. D. (2004). Mental health: The pre-independence scenario. In S. P. Agarwal, D. S. Goel, R. L. Ichhpujani, R. N. Salhan, \& S. Shrivastava, Mental health: An Indian perspective (pp. 25-29). New Delhi, India: Reed Elsevier India Private Limited.

Singh, S. B., Chandra, S., \& Chakraborty, S. (2018, October 25). A brief survey on music intervention in western and non-western (Indian) music. MOJ Biology and Medicine, 3(4), 190-194. https://doi.org/10.15406/mojbm.2018.03.00097

Sobana, R., Sunder, S., \& Jaiganesh, K. (2020, June 11). Music therapy for pulmonary rehabilitation in chronic obstructive pulmonary disease [COPD] patients- An interventional trial. International Journal of Current Research and Review, 12(12), 26029. http://dx.doi.org/ 10.31782/IJCRR.2020.12126

Sundar, S. (2006, July 1). How to introduce standards for competent music therapy, education and training in countries where music therapy is in an early stage of development-An interview with Micheal G. McGuire. Voices: A World Forum for Music Therapy, 6(2). https://doi.org/10.15845/voices.v6i2.254

Sundar, S. (2012). 5-8. Chennai, Tamilnadu, India: Chennai School of Music Therapy. Retrieved November 2020

Sunitha, G., Algoodkar, D. S., \& Smitha, P. S. (2018, April-June). Effect of Indian classical music therapy on depression, anxiety and stress levels in patients with depression measured by DASS-21: A pilot study. International Journal of Physiology, 6(2), 128-133.

https://doi.org/10.5958/2320-608X.2018.00067.7

Vinaya, D. (n.d.). Music therapy. Retrieved November 28, 2020, from https://drvinayaswellnessconcepts.com/music-therapy/

Wigram, T., Pedersen, I. N., \& Bonde, L. O. (2002). Models and methods of music therapy. In T. Wigram, I. N. Pedersen, \& L. O. Bonde, A comprehensive guide to music therapy: Theory, clinical practice, research and training (pp. 113-150). London, United Kingdom: Jassica Kingsley Publishers. 